\title{
Opportunity Recognition in High Tech and Regulatory Environment: A Study of Product Based Indian Telecom Start-ups
}

\author{
Prageet Aeron \\ Rekha Jain
}

W.P. No. 2011-02-09

February 2011

The main objective of the working paper series of the IIMA is to help faculty members, research staff and doctoral students to speedily share their research findings with professional colleagues and test their research findings at the pre-publication stage. IIMA is committed to maintain academic freedom. The opinion(s), view(s) and conclusion(s) expressed in the working paper are those of the authors and not that of IIMA.

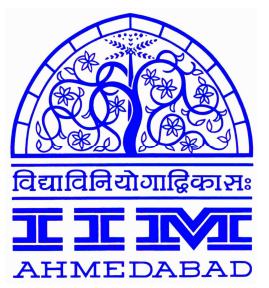

INDIAN INSTITUTE OF MANAGEMENT

AHMEDABAD-380 015

INDIA 


\title{
Opportunity Recognition in High Tech and Regulatory Environment: A Study of Product Based Indian Telecom Start-ups
}

\author{
Prageet Aeron \\ Assistant Professor, Jindal Global Business School, Sonepat, Haryana, India \\ Email: paeron@jgu.edu.in \\ (All correspondence to be sent at this e-mail id) \\ Dr. Rekha Jain \\ Professor and Idea Telecom Executive Chair \\ Indian Institute of Management, Ahmedabad, Gujarat, India \\ Email: rekha@iimahd.ernet.in
}

\begin{abstract}
Opportunity recognition forms the first step of entrepreneurship. Off late entrepreneurship research has looked at opportunity recognition from varied lenses with entrepreneurial learning forming the core of most scholarly work. However opportunity recognition in high tech sectors is slightly different due to a high component of knowledge intensiveness inherent in such sectors and has been largely ignored in most work. So, we explore a specific high tech sector in the paper to understand and further the existing concepts within opportunity recognition process. We choose the Indian telecom sector as the context of the study and using an inductive case based approach arrive at conceptual combination as the dominant form of idea generation. The regulatory environment was found to acts as an enabler for the new ideas to flourish. We also bring in the idea of dynamic customization as the driving force behind the venture akin to symbiotic relationship present between organisms in the nature.
\end{abstract}




\section{Opportunity Recognition in High Tech and Regulatory Environment: A Study of Product Based Indian Telecom Start-ups}

\section{Introduction}

The field of entrepreneurship is important for scholarly examination as it holds within its realm several unanswered questions that can help shed light on missing link in economics literature regarding the formation of the firm. Entrepreneurship is the common link between invention, innovation and new product development literature. Identifying and selecting the right opportunity for new businesses is arguably the most important task of a successful entrepreneur (Stevenson et al., 1985). Consequently, explaining the discovery and development of opportunities is a key component of entrepreneurship research (Venkataraman, 1997). But we are still far from developing a comprehensive theory of opportunity recognition.

This paper builds on existing theoretical and empirical studies in the area of entrepreneurial opportunity to propose a holistic theory of the opportunity identification process, with specific reference to the field of high-tech start-ups and specifically telecom based start-ups. The rationale behind this narrow focus is firstly, high-tech firms are important because they are seen by many governments as having a pivotal role to play in the regeneration and growth of national economies (OECD, 2003) and secondly such firms work in a dynamic environment. A wealth of evidence suggests that new, small firms grow faster (Wagner, 1994; Tether and Massini, 1998; Brixy and Kohaut, 1999), create more net jobs (Robson, Gallagher, and Daly, 1993; Hart and Oulton, 1999), and distribute wealth more effectively (Schumpeter, 1934, 1942). In the last 25 years, two-thirds of the net new jobs and $95 \%$ of the radical innovations have come from these entrepreneurial businesses (Timmons and Spinelli, 2003) in a developed market like US. The potential of such large scale employment in developing markets through such start-ups is immense especially in telecom sector in India which has been growing at a phenomenal double digit rate since 2003 to present. A better understanding of effective opportunity recognition processes used in such technology sectors would have benefits in helping government develop and refine appropriate policies and support programmes. As for the context being telecom start-ups, telecom start-ups operate in a knowledge intensive and regulatory environment which makes starting business in telecom domain comparatively more challenging as compared to other high tech businesses.

The main contribution of the paper is to bring about the difference between telecom start-ups and the other high tech start-ups in the opportunity recognition process and to identify the presence of 
conceptual combination as the main idea generating mechanism. The paper also identifies coevolution or dynamic customization as a source of opportunity recognition among the Indian start-ups which may as well be extendable to other developing countries. The paper is organized as follows, we begin with discussion on definition of opportunity recognition, a brief literature review, then move on to our methodology, case descriptions, analysis, conceptualization and finally we end with discussion.

\section{Definition}

Kirzner $(1973 ; 1979)$ defines an opportunity as special knowledge an entrepreneur acquires about goods or services sold in new markets or combined and sold at a profit. However, according to him ideas become an opportunity only when their commercial value is recognized. DeBono (1978) defines opportunity as a "course of action that is possible and worth pursuing." $\mathrm{He}$ also points out that recognizing opportunities involves non-linear or lateral creative thinking, that is, "thinking outside the box." Hulbert et al. (1997) state that a business opportunity is the chance to meet an unsatisfied need that is potentially profitable. Ardichvili et al. (2003) define it as the chance to meet a market need (or interest or want) through a creative combination of resources to deliver superior value. Christensen, Madsen and Peterson (1994) define opportunity recognition as either perceiving a possibility to create a new business, or improving the position of an existing business, in both cases resulting in a new profit potential.

Extant literature defines opportunity recognition and also separately discusses opportunity development to further elaborate on it. We slightly differ from this distinction and we specify the opportunity recognition to have taken place when the idea has been concretized and external validation has been sought on the ideas. We also hold that this is irrespective of the fact whether the firm has been founded or not. For us the closure of opportunity is the point when the idea has stabilized to the point that going further what is left from the perspective of idea is to only implement or exploit it using available resources. In other words we consider opportunity development within the gambit of opportunity recognition itself as unless the opportunity has been developed to an extent that it can be exploited it is merely a speculation.

\section{Opportunity Recognition Literature}

The focus of entrepreneurship research changed in the late 1980s and early 1990s with authors proposing a more holistic approach to the study of entrepreneurship as opposed to an overemphasis on the personality traits of the entrepreneur (Gartner, 1985, 1988; Bygrave and Hofer, 1991). Several models of opportunity recognition have been presented during the last two decades (Bhave, 1994; Schwartz and Teach, 1999; Singh et al., 1999; De Koning, 1999; Sigrist, 1999). These models are 
based on differing assumptions borrowed from a variety of disciplines, ranging from cognitive psychology to Austrian economics. While these attempts have contributed to our understanding of opportunity identification, but they primarily concentrate on only one of the many aspects of the process for example, De Koning (1999) and Hills et al. (1997) focus on the social network context; while Shane (1999) focuses on the prior knowledge and experience necessary for successful recognition. However, this focus on specific factors is often at the expense of other equally important factors in the same study, effecting causality.

Hayek (1945) had recognized the role of knowledge and information dispersal in entrepreneurship and his work has further been built upon by Venkataraman, (1997), Shane and Venkataraman (2000), Shane, (1999), Eckhart and Shane, (2003). Ardichvili et al., (2003) use Dubin's (1978) theory building method to impress upon the role of prior knowledge related to markets, industry, customers etc. Knowledge in the form of experience has already been established to be an important construct in the opportunity recognition process (Vesper, 1990). Shane (1999) has specifically looked at the role of technological breakthrough and it was found that when same information was presented to different individuals with differing prior knowledge it led to different opportunities being recognized. Clearly prior knowledge plays a critical role in the opportunity recognition process but how the interplay between information asymmetry and experience lead to opportunity recognition is still not clear.

Gartner et al. (2003) have talked about two differing ontological positions in entrepreneurship theory one related to the "positivist or realist" position wherein discovery approach is propagated with opportunity waiting to be discovered. The other ontological position is related to interpretive or social constructionist perspective on reality which is the enactment approach. Dutta and Crossan (2005) have talked about parallel entrepreneurial opportunities namely the Schumpeterian view and the Kirznerian view. The authors adopting the Schumpeterian view believe that opportunities are created and the role of entrepreneur's personality traits affects the way the opportunities are discovered. Kirznerian view on the other hand focuses on knowledge and information asymmetry that exists between the people in the market. Therefore idiosyncratic knowledge plays a significant role in the opportunity recognition.

Another growing strand of literature relates cognition to opportunity recognition and entrepreneurship. Baron (1998) and then Busenitz and Barney (1997) bring out the fact that entrepreneurs use heuristics and biases in decision making and this enables them in taking much less time in arriving at conclusions even in very complex situations. Ward (2004) connects creativity to cognition and knowledge and points out that depending upon how knowledge is utilized through 
cognition, knowledge will either provide a new opportunity or may block the path of an opportunity. He points at conceptual combination, analogical reasoning and a few others as possible ways of generating novel ideas along with method of abstraction and problem formulation of the individual which may invoke the way knowledge is stored and information retrieved. Lumpkin et al. (2004) too have argued in favour of creativity based approach to opportunity recognition and have proposed a five step model inspired from Csikszentmihalyi (1996) basic elements of creativity. The fives steps proposed are preparation, incubation, insight, evaluation and elaboration with first three stages describing discovery and the other two describing formation.

Corbett (2005) extends the creativity and knowledge aspect by bringing in learning asymmetries or the difference in the way people assimilate knowledge. This difference is due to the differences in the learning process that different individuals predominantly follow (assimilative, convergent, divergent or accommodative). Also each of the learning process is effective to differing degrees in the different stages of opportunity recognition. Lumpkin and Lichtenstein, (2005) have proposed a conceptual model for opportunity recognition as a process of organization learning with three forms of learning namely behavioral, cognitive and action learning impacting discovery and formation process differently. Cognitive learning has the potential of opening up new markets whereas behavioral learning seems more adaptive in nature helping more in the formation process. Action learning enables course correcting process of organizations which enables both the cognitive and behavioral learning by questioning the existing norms and thus leading to double loop learning (Argyris and Schoen, 1978). Dutta and Crossan (2005) too have positioned the opportunity recognition process as a learning process and have applied the $4 \mathrm{I}$ (Intuition, Interpretation, Integration and Instutionalization) framework of organizational learning to the opportunity recognition process and have further tried to bring a convergence in the ontological positions of Schumpeterian and Kirznerian entrepreneurship by linking intuiting and interpreting to enactment and integration and institutionalization to objective reality. However, there is a general agreement among the organizational learning researcher about the opportunity recognition being multi-level and happening across multiple time frames.

Above mentioned literature informs us on various dimensions but does not offer some specific insights about more knowledge intensive sectors. Although prior knowledge and experience have been listed down as important drivers but how exactly new idea comes up in such a setting which requires deep understanding of technology has not been adequately addressed. Through this paper we try to answer the questions regarding the process of opportunity recognition among the high tech (knowledge intensive) start-up firms, and whether the ways in which ideas get incubated in such firms differ from the ways it happens elsewhere. Where does the regulatory environment come in at the 
stage of opportunity recognition, how does it contribute if at all to the process. We will try to answer these questions in the coming sections using telecom start-ups as the context.

\section{Methodology}

We use a case based inductive approach to try and answer the questions posed by us. Case based study is ideally suited to answer questions related to process inquiry as well as answering how and why kind of questions (Eisenhardt, 1989; Yin, 1994). Two important aspects of multiple case based studies are case sampling and number of cases to be studied. According to Eisenhardt (1989) and Miles and Huberman (1994) or purposive sampling a good sartegy is maximum variation on various parameters. This is particularly good strategy for process based studies as firms which are far apart in term sof various parameters could be studied for theoretical or literal replication and thus help in developing robust theory. So polar sampling of this kind ensures external validity. In terms of number of cases the idea to reach theoretical saturation and generally, three or more case studies are helpful in this respect.

We identified 12 different companies within the telecom sector operating in different domains such as voice over Internet Protocol (VoIP) infrastructure development, technology platform for offering value added services, equipment manufacturers, network management. All the companies were product companies looking to sell their end product to either telecom service providers or the Internet service providers and none of them was purely a service based company. Also all these companies had their registered corporate head offices in India and none of them were promoted by large diversified groups. The reason for the above filter was that companies started out of India would face a different external environment in terms of the ability to raise capital as well as the risk appetite of the entrepreneurs and investors as compared to those in India. Although it can be argued that the process of opportunity recognition may not be country specific but an additional objective of our work was to understand the way Indian technology entrepreneurs think about opportunity recognition and this made the above filter mandatory. Similarly a company promoted by a diversified conglomerate would more be a diversification move rather than a start-up company. Our basic assumption here is that an individual entrepreneur or a group of co-founders with no or little experience of entrepreneurship would look at opportunities and the risk in different ways as compared to a conglomerate backed venture. So we were looking for companies with above characteristics to be able to unravel the process of opportunity recognition among technology oriented entrepreneurs who started from scratch and were mostly first generation entrepreneurs. 
We finally chose 3 companies based on our strategy of maximum variation. Table -1 below gives details regarding the firms and their characteristic differences.

Table-1: Sample firms with differences across various parameters

\begin{tabular}{|l|l|l|l|}
\hline & \multicolumn{3}{|c|}{ Company Name } \\
\hline Parameter & \multicolumn{1}{|c|}{ C1 } & \multicolumn{1}{c|}{ C2 } & \multicolumn{1}{c|}{ C3 } \\
\hline Founded & 2005 & 2001 & 2002 \\
\hline Technology & $\begin{array}{l}\text { WiMax } \\
\text { (wireless) }\end{array}$ & VoIP & $\begin{array}{l}\text { Circuit emulation } \\
\text { over Ethernet }\end{array}$ \\
\hline Area of operation & $\begin{array}{l}\text { Equipment } \\
\text { development }\end{array}$ & $\begin{array}{l}\text { Platform } \\
\text { development }\end{array}$ & $\begin{array}{l}\text { Equipment } \\
\text { development }\end{array}$ \\
\hline Hardware/software & Both & Software & Both \\
\hline Incubation & No & $\begin{array}{l}\text { Yes } \\
\text { (IIT Madras) }\end{array}$ & $\begin{array}{l}\text { Yes } \\
\text { (IIT Bombay) }\end{array}$ \\
\hline VC investment & No & Yes & Yes \\
\hline Product & Base station & Switch and & First mile access \\
& & middleware & equipment \\
\hline Patents & Yes (Pending) & No & Yes \\
\hline Success/Failed & Success & Success & Failed \\
\hline
\end{tabular}

We sent letters to all the three chosen companies and sent mails to them identifying ourselves and explaining the purpose of our work. We requested each of the companies to let us have a session with each of the founders to understand and assess the conditions during the opportunity recognition process. Among the 3 companies one of the companies is no longer in existence and had to be closed down due to various business reasons. Since we are not looking at the quality of opportunity recognition or the impact of opportunity recognition on the success of the venture we could include the company into our analysis. We talked to the co-founders in all cases separately and this also helped in triangulation of data that we collected. We conducted 3-4 interviews per company (total of 12 interviews) and most interviews lasted around 1.5-2 hours. Our respondents were the entrepreneurs as they are aware of every aspect of their company in complete details. Apart from the founding members we also talked to earliest employees of the teams wherever possible. We also collected newspaper report and other archival data from the company websites. Once data was collected, the interviews were transcribed and converted to case histories to focus on the questions to be answered. 
These write-ups were sent to respective firms for their approvals before we began our analysis to ensure authenticity of data. This was followed by analysis and subsequent conceptualization of the insights gained into a model of opportunity recognition.

\section{Case Studies}

\section{Company C1:}

C1 was founded in Bangalore in the year 2005. The two founding members were highly educated with post graduate degrees in technology; one had a MS from US and other was a MS from India. Both founding members were first generation entrepreneurs without any prior start-up experience. Both the founding members were with in their mid-thirties. First founder worked for a well known telecom equipment manufacturer $(\mathrm{MNC})$ in various technical roles especially related to manufacturing of hardware. Due to personal reasons he came back to India and then he joined as a senior architect in a leading Indian telecom solution provider company at Bangalore. It is here that he got an opportunity to prepare business proposals for new projects and also got a chance to lead the team from the front. He himself admits the change that this brought about in his attitude. According to him, "I should be thankful to [XYZ Co.] for that as they allowed a young person like me to carry out those exercises. Joining [XYZ Co.] was very good as it gave me an exposure about how the Indian wireless market was shaping up and stuff like that. So I learnt a lot of things especially what to do and what not to do". Co-founder was more active in technical roles and had about 8 years of experience in development related to telecom products. Both the founders gave up their job to start the company.

Initial opportunity that presented itself before company $\mathrm{C} 1$ was the development of a 3G/UMTS small base station for a large MNC. The project was proposed by one of the founders while he was working for a leading telecom solution company in India. His team was closely interacting with MNC team and in the in process of discussion among the team members of both the firms, detailed idea for the project emerged. The MNC team was looking to develop a base station that had low power consumption, low cost and had a much smaller scale as compared to the conventional base stations. The parent company for which the founding members were working could not take up the project due to certain constraints, but founding members were highly optimistic of project's feasibility and one of them developed the business plan for the same. He searched the market for investors, had discussions on the business plan within his project team and once convinced of being able to raise some money, together he and his associate founded their own company to pursue this opportunity.

The second opportunity was recognized when founder was trying to solicit funds for the $3 \mathrm{G}$ base 
station development that the company was trying to make. Several investors (mostly US based) advised him to get in to the WiMax space. Around mid 2005, WiMax was being promoted across the world as the next major technology that could change the existing communication paradigm. Around the same time Indian telecom regulator Telecom Regulatory authority of India (TRAI) too announced its tentative policy direction with respect to WiMax. The founding team and other members of the company together deliberated on this issue and then decided to enter the WiMax domain. In the process they weighed their strengths and had discussions among themselves about the business models for WiMax, possible customers, about the problems of 3G platform dependency on large vendors, learning WiMax and finally they decided to develop a small base station that could be mounted on a tower or house top. The company went along with its development work and was able to bring its product into the market and is today among admired start-ups in the field of WiMax from India.

\section{Company C2:}

C2 was founded in the year 2000-2001 in Hyderabad. Both the founders (A, B) were highly educated with a post graduate degrees in management; Mr. A held a BS degree from IIT in Chemical Engineering whereas Mr. B held a degree in Mathematics at the under graduate level. Both the founding members were first generation entrepreneurs without any prior start-up experience. Both the founding members were within their late twenties to early thirties. Mr. A worked for a well known software development company as a project manager. Then he joined a well known Indian ISP and headed the business development activities related to web services division. It is here that he got an opportunity to lead the team from the front. In both his jobs he acquired experience related to real time network services development. Co-founder (B) had no prior experience and he joined the same ISP as the other founder as a (fresher) management trainee. He was to look after sales and marketing role for the web services division of ISP which was headed by the other founding member (A). Both the founders gave up their job to start the new company.

The initial idea that the founders had was to develop an application that would enable the customers to get access to their e-mails through ordinary phone line using text to voice converter engine. Both the founders were convinced about the feasibility of this application and developed a business plan wherein they expected to scale-up through a subscription business model. They even started working on developing the prototype on their own. But when they started visiting various investors for funds they got a different feedback. The investors stressed upon them the fact that the kind of service that they were planning was very difficult in India due to the infrastructure bottlenecks. Moreover, they could not provide for the infrastructure by themselves but could only act as technology providers for 
an existing infrastructure. According to the CTO of the firm,

"But yes, there was a lot of learning in talking to these VCs and other people in the industry. We came to realize that yes we cannot do everything".

"The key was migration was from we will do all to we are only a technology provider. This did not happen in the beginning, it was not like we talked to one VC and dropped all our ideas, it does not happen like that, slowly and slowly as you talk to people they start giving you clues as to this is the kind of things you should do. There were many guys like Jump start-up and other Bangalore guys we had met almost everybody".

During this time regulation was passed making VoIP services legal between PCs in India to phones, mobiles and PCs abroad. The founders who were developing convergence engine and were trying to develop voice based application found VoIP services to an ideal opportunity for them to be able to use their technological skill. The business idea was to develop VoIP infrastructure for ISPs who already had network and other infrastructure of their own and let them offer the VoIP services using the product developed by the company. Later the company got invested by a VC and shifted its base to Chennai under the aegis of the TeNeT group of IIT Madras and has been one of the pioneers of VoIP software product in India.

\section{Company C3:}

C3 was founded in late 2002 in Mumbai. All the three founders were highly educated, one with a PhD in Electrical Engineering from IIT, second with post graduate degree in management from an university in US and a BS from IIT and the third holding a post graduate degree in Electrical Engineering from IIT. First two of the founding members were in their early forties, whereas one among them was in his mid twenties. First founder worked as a faculty member at a leading institute of technology in the Electrical Engineering department and had 5-6 years of consulting experience in the area of networking and was actively engaged in research dealing with next generation network architecture. He was a first generation entrepreneur with no prior experience related to working for a technology company. Second founder of the firm was running a successful family owned business related to transport and clearing house. In early nineties he diversified his family business into certain customer premise telecom equipment manufacturing such as Modems and owned his owns small manufacturing unit in Mumbai. The third co-founder had about two years of experience related to software development with a major Indian company before he joined the MS programme at IIT. Neither the first nor the second founder gave up his job to start the company; third founder was a 
fresher and was on a look out for a suitable job.

The first founder and his MS student (third co-founder of company C3) had regular interaction during the project phase of the latter. During these interactions they discussed the way telecom and networking industry would move in near future. It was recognized that the future networks would essentially be Internet protocol (IP) based packet networks and the circuit switched networks would slowly have to be replaced by the next generation networks. The same network would have to be used to carry both data and voice. In Europe and USA the networks carrying data were showing higher growth rates in comparison to the voice minutes and the trend was showing a growth across the globe. But before the next generation networks could be completely replaced a transition stage was to be witnessed where most networks would be a combination of different kinds of network topologies. However, the last mile connectivity in India and similar developing nations was seen as a major bottleneck. So the need of the hour was to provide a multi service interface that could use the existing infrastructure but provide the data, voice and video capabilities with the minimum change in the equipment, with minimum capital expenditure and highest quality of service. Founders of company C3 were looking to develop such a multiple service interface with Ethernet at the core of the technology as it was well understood and simple and cost effective to deploy. The founders also strongly felt that the growth of broadband subscribers would be a key growth driver for the telecom companies in India. The first and second founder had a common contact in the industry who was in a senior position with one of the telecom service providers and had extensive telecom related experience working in India and abroad. They contacted him and he helped them in reconceptualizing their ideas to a form which could be endorsed by the industry. The existing technologies for broadband were mostly xDSL based and suffered from overheads and issues of service provisioning and management when integrated with IP based networks. So, they could see a substantial market for a technology product that could bridge the above problems of low cost, maximum and efficient usage of existing infrastructure, triple play facility with better service provisioning and management. Although the company went forward with its plans of manufacturing and did achieve some success in its development efforts but due to certain business reasons the company could not sustain itself and was closed down in mid 2007.

\section{Analysis}

For company $\mathrm{C} 1$ the first opportunity emerged from previous work experience, understanding of the business environment and the presence of an active social network. The MNC with which the founder's team was working wanted to develop products suited to developing countries with low power output and low power requirement, low cost as well as smaller scale associated with 
uncertainty related to the new product demand actually picking up. Moreover, lower cost of product also enables chances of mass acceptability and deployment across the segment of population who value such services.

The requirement could be satisfied by bringing together two divergent concepts. One was the concept of the base station being high end equipment with ability to support a large number of users and the other was the idea of affordability and limited number of users. Founders of company C3 were successfully able to merge these two ideas by questioning the existing norm of base station being a large expensive piece of equipment. This is analogous to the process of double lop learning where one questions the existing paradigm of thought and creates a new norm. So there was a conceptual combination brought about by the process of double loop learning. The founders of company C3 build their mental model of future communication needs and perceived the idea to be feasible and worth pursuing.

In the second phase the investors played a major role in recognition of the opportunity related to the choice of WiMax. However, from the perspective of idea evolution the previous thought process of compact and low power base station was extended and combined with a more commercially promising technology. Here again the mental model of the entrepreneur was modified by the feedback he received from the evaluators (mostly the potential investors). In both the instances idea evolved by digging into own experience and knowledge to understand and explicate the situation followed by self assessment, deliberation and discussion with team, and finally accepting the opportunity at the organizational level by either founding of the new venture or adopting a new strategic direction.

In contrast to the company $\mathrm{C} 1$ entrepreneurs at $\mathrm{C} 2$ started their company without any concrete idea and were deliberately looking for a strong enough opportunity to take up seriously. For company $\mathrm{C} 2$ too the initial idea emerged from previous experience, understanding of the business environment and a vision or mental model of the entrepreneurs about the possible shape of communication infrastructure in future. As early as 2000 they were thinking of convergence bringing together two divergent concepts of voice communication and data communication together when most of the networks looked at the two as different. The initial idea was to develop a text to voice application that could read the e-mails and one could simply access e-mail by picking up the wireline phones. Again we see an instance of conceptual combination. But this intuition was further developed in to a concrete idea in incremental steps. For example the detailed interaction with the investors played a major role in realization of the limitations that the founders were faced with and the investors pushed the founders to think of ways to overcome those impediments. The evaluation by the investors made 
the entrepreneurs realize that they could not do everything themselves and they needed to bound their idea within ground realities. Here we see an instance of behavioral or adaptive learning taking place that modified the initial mental model and corresponding idea with the feedback being incorporated into the original idea by the entrepreneurs. But finally it was the government regulation that enabled the team to clearly decide upon their future path. So founding members, their interaction with their social network as well as potential investors and finally the government regulations all played a role in the recognition of opportunity and zeroing on to the specific development path and the product to be developed.

In company $\mathrm{C} 3$ too the prior research experience of the first founder in the field of networking and shared vision among the founders about the possible shape of communication requirements in future played a major role in the opportunity recognition process. The initial idea evolved through numerous interactions between the first founder and the third co-founder during the latter's MS thesis days. The problem of infrastructure bottleneck because of copper based last mile connectivity and corresponding problems in providing other enriched services including both data and video on the given network were realized. The existing wireline based voice networks were time division multiplexing (TDM) or circuit based and offered several features like guaranteed quality of service, fast restoration and reliability whereas packet networks offered better utilization and scalability. The idea was to combine both the features using Ethernet as the core at as low cost as possible. So again we see that conceptual combination was resorted to for idea generation. But this intuition was further developed in to a concrete idea due to detailed interaction with an industry expert that led to the realization of the actual problems being faced by the service providers and corresponding opportunity recognition. Here again it was realized that the kind of products available with telecom equipment majors were high end, not just in terms of cost but also the scales it could support whereas the telecom service providers in India were looking at entry level equipment due to uncertainty related to the demand for broadband and other services picking up in India. So founding members, their interaction with their social network and finally the government regulations which by the time had decided to take a technology neutral approach and had allowed unrestricted access through both wireless and wireline, all played a role in the recognition of opportunity and zeroing on to the specific development path and the product to be developed.

We see that in two of the cases the customization or India centric need was identified. Let us examine this facet more closely. This also requires a look at the telecom industry environment in India during the period from 1999 to 2004-05. The Indian telecom industry saw unprecedented double digit growth across the length and breadth of the country specially related to voice related service. This growth 
brought in several players in to the fold who became telecom service providers. However, the new growth was expected to come from data related and other value added services as was seen across the globe. But there was a catch here that Indian customers had been slow in warming up to Internet related services and even wireless services had taken over 10 year to actually pick up due to high cost of services in the initial days. Indian customers have often been described as "most price elastic and also most quality conscious" which at times is quite contradictory. So none of the new telecom service providers (TSPs) or the Internet service providers (ISPs) were ready to implement new services on a large scale and most companies wanted to grow as the demand picked up instead of committing to huge investment at any particular instant of time. Now all the large telecom equipment manufacturers (mostly MNCs) had high end equipment that was not just costly but was designed keeping in mind the scales required in western countries. This kind of large and risky investment was something that none of the TSPs or ISPs were comfortable with. The requirement of the time was entry level, low cost high quality equipment, that could be upgraded in terms of both technology and scale in the future if required but which was not readily available. This played a prominent role in opportunity recognition process.

The Indian companies on the other hand although start-ups cold offer such products and they could grow with the user company as the demand for the product grew. So, this possibility of co-evolution was a major factor that enabled new ideas to form. This phenomenon although akin to customization is more powerful than simple customization as what it entails it dynamic customization along a required trajectory.

Again the Bhave (1994) classification between entrepreneurs who start first and then find an opportunity worth pursuing and those who first find an opportunity and then start on their own is highlighted by the cases $\mathrm{C} 1, \mathrm{C} 2$ and $\mathrm{C} 3$. Accidental or deliberate opportunity recognition seems equally probable in the telecom start-ups.

Another general observation that can be made here is the role of personality traits. The role of motivation in starting such an endeavor or even persisting with the adaptive and at times lengthy process of opportunity recognition, creativity in recognizing new ideas, self confidence and optimism in subjecting the ideas to scrutiny and finally zeroing on or stabilizing with an idea are all equally important in the process. At no point can the role of such personality traits be ignored in the opportunity recognition or entrepreneurship in general.

A generalized process model combining insights from above analysis has been presented in figure 1 . 


\section{Conceptualization}

We will now try to bring the various elements from existing theory, case descriptions and try to generalize and arrive at a conceptual framework of the process of opportunity recognition among the telecom product based start-ups. The entrepreneur is in possession of knowledge and this knowledge may be classified as technology related, management related, and market related. We have seen that the average education level of the entrepreneurs in the telecom domain is high. This is predictable to some extent as the role of knowledge especially technical knowledge which would comprise knowledge about hardware, software, protocols stacks, data transmission, certain standards etc is a prerequisite to be able to enter the telecom domain. To be able to offer any product in the telecom domain understanding of how the telecom products work would require a well grooved technical background as well as a deep understanding of how the telecom market works. So higher education and relevant industry experience translates into higher stock of knowledge and also higher absorptive capacity (Cohen, Levinthal, 1990). The entrepreneurs have access to information that is received and processed by them from varied sources such as mentors, professional acquaintances and friends, regulatory announcements, investors or potential investors, potential customers and also standard bodies. Thus the sources of information act to create or reduce the information asymmetry among the entrepreneurs. However, the information has to be processed for relevance and quality by none other than the entrepreneur. Presence of high stock of knowledge and relevant information or cues enables the entrepreneur to be able to build mental models or schemas about how the communication needs will change in future and consequent requirements of the telecom market. The above process can be mapped as a cognitive learning process wherein the information from relevant sources is analyzed by the entrepreneur employing her existing stock of knowledge. This learning process transforms and adds to the stock of existing knowledge and as a result a mental model or a schema is formed that is the basis of entrepreneur's understanding of the environment and its future requirements. The cognitive learning clearly plays a very prominent role in the ability of the entrepreneurs active in the high tech industries in extrapolating their ideas to the future.

Guided by these mental models entrepreneurs are able to unravel existing communication or data needs not being served appropriately or new efficient or cheaper ways of communicating or even a solution to a problem that does not exist. This is a very creative activity wherein absorptive capacity of the entrepreneur plays a very important role as the entrepreneur applies certain heuristics to formulate tentative idea or ideas with technology guiding her in what is achievable and what is not. From above description of the case studies it can be concurred that conceptual combination as the process of creative idea generation has been applied by entrepreneurs in the telecom start-ups. These 
tentative ideas are then subjected to scrutiny of different sources including possible stakeholders and team members. This is the process of idea evaluation and feedback from these sources (not all may be active) influences the mental model of the entrepreneur, which in turn leads to idea refinement or modification or even completely new idea. The entrepreneur may completely choose to ignore any feedback at this point and go ahead with her ideas depending upon the self efficacy or the optimism inherent in the entrepreneur as well as her own conviction in her mental model. The role of investors or potential investors is of particular significance at this point because in case of easily forthcoming finance from investors certain legitimization of the idea has been already achieved. Finally the idea is concretized within the mind of the entrepreneur and it is at this point that opportunity has been recognized. This may be followed by opportunity development wherein further concretization of the idea may be achieved by documenting and producing a business plan. The entrepreneur may choose to start the actual venture at any point in the above process irrespective of idea having being formulated or not.

\section{Discussion}

Some of the findings from the above section can be summarized as follows:

F1: Regulatory changes and changes in the telecom technology standards create stimulus for potential new services and potential new products in a regulated telecom environment.

F2: Information delivered by information sources mediates the relationship between entrepreneur's knowledge and the mental model that is developed and the mental models develop through the process of cognitive learning.

F3: The dominating mechanism for transformation of mental model to prospective ideas among the telecom start-ups seems to be through conceptual combination.

F4: The process of idea refinement is an adaptive process that involves several iterations and the dominant learning mechanism here is action based or behavioral learning.

F5: Investors like private equity funds, venture capital funds play a proactive role in idea refinement even if they do not invest in the idea.

F6: The social network of entrepreneurs play dual role in the opportunity recognition process both as sources of information as well as the first cut evaluators of the ideas. They by endorsing the ideas provide legitimacy to the idea for further evaluation. 
Above findings reflect two starking differences between the telecom start-ups and the other high tech start-ups. First difference is as per expectation as mentioned at the beginning of the paper, that is precisely the role of technology standards and regulatory institution in the opportunity recognition. Second difference arises on account of the requirement of entry level equipment and a need to coevolve with the service providers which we have called dynamic customization. The other findings are equally applicable to most other high tech start-ups but our contribution lies in the fact that we have extracted these findings from grounded data in a context which was hitherto unexplored, i.e. is the Indian product based telecom start-ups. That our findings reaffirm adaptiveness, behavioral learning and the role of social networks in the opportunity recognition further goes on to strengthen the existing beliefs about these constructs. However, we do acknowledge that this work looks at a smaller number of data points although statistical conclusion is never the objective of case based works.

Future work could look into operationalizing and confirming the above mentioned findings in a statistically significant sample. We feel operationalization of learning and knowledge variables offers a very interesting direction of research not just for opportunity recognition and entrepreneurship but also strategic management research could gain from such work. 


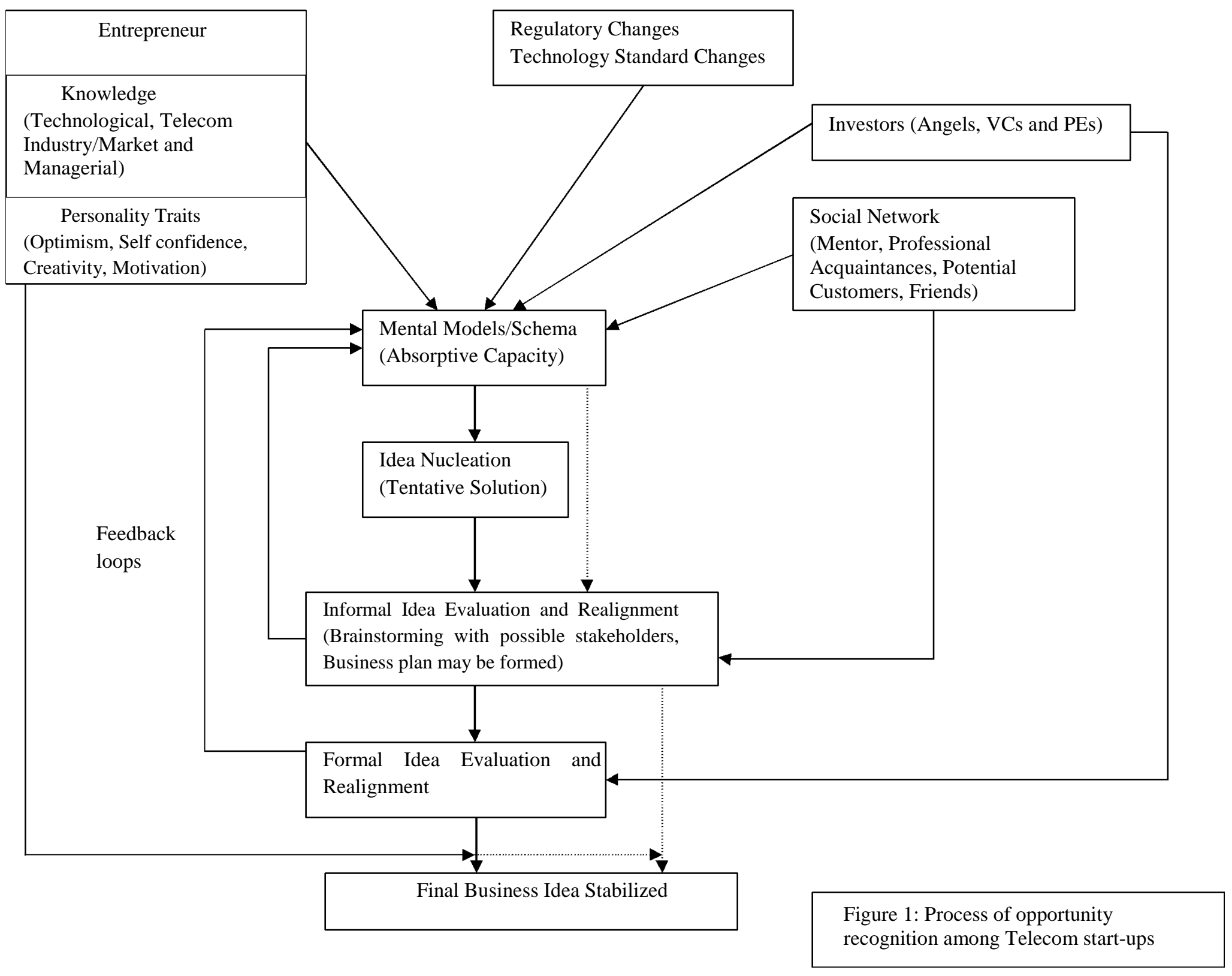




\section{References:}

Alvarez, S. A., Busenitz, L., 2001. The entrepreneurship of resource-based theory. Journal of Management, 27, 755-75.

Argyris, C., Schoen, D., 1978. Organizational Learning: A theory of action perspective. AddisonWesley, Reading, MA.

Archdvili, A., Cardozo, R., Ray, S., 2003. A theory of entrepreneurial opportunity identification and development. Journal of Business Venturing, 18, 105-123.

Baron, R., 1998. Cognitive mechanisms in entrepreneurship: Why and when entrepreneurs think differently than other people. Journal of Business Venturing, 13(4), 275-294.

Bhave, M.P., 1994. A process model of entrepreneurial venture creation. Journal of Business Venturing, 9, 223-242.

Brixy, U., Kohaut, S., 1999. Employment growth determinants in new firms in eastern Germany. Small Business Economics, 13, 155-170.

Bygrave, W., Hofer, C.W., 1991. Theorising about entrepreneurship. Entrepreneurship Theory and Practice, 15(4), 13-22.

Cohen, W.M., Levinthal, D.A., 1990. Absorptive capacity: A new perspective on learning and innovation. Administrative Science Quarterly, 35, 128-152.

Corbett, A.C., 2005. Experiental learning within the process of opportunity identification and exploitation. Entrepreneurship Theory and Practice, 25 (4), 473-491.

Csikszentmihalyi, M.,1996. Creativity. New York: HarperCollins.

De Koning, A., 1999. Conceptualizing opportunity recognition as a socio-cognitive process. Stockholm, Centre for Advanced Studies in Leadership.

Dubin, R., 1978. Theory Building, second edition. Free Press, New York.

Dutta, D. K., Crossan, M. M., 2005. The nature of entrepreneurial opportunities: Understanding the process using the 4I organizational learning framework. Entrepreneurship Theory and Practice, 29, $425-449$.

Eckhardt, J., Shane, S., 2003. Opportunities and entrepreneurship. Journal of Management, 29, 333349.

Eisenhardt, K. M., 1989. Building theories from case study research. Academy of Management Review, 14(4), 532-550.

Gartner, W.B., 1985. A framework for describing and classifying the phenomenon of new venture creation. Academy of Management Review, 10(4), 696-706.

Gartner, W.B., 1988. Who is an entrepreneur is the wrong question. American Journal of Small Business, 13(1), 11-32.

Gartner, W.B., Carter, N.M., Hills, G.E., 2003. The language of opportunity. In C. Steyaert \& D. 
Hjorth (Eds), New movements in entrepreneurship (pp. 103-124). Cheltenham, UK: Edward Elgar.

Hart, P., Oulton, N., 1999. Gibrat, galton, and job generation. International Journal of the Economics of Business, 6(2), 149-164.

Hayek, F., 1945. The use of knowledge in society. Am. Econ. Rev. 35 (4), 519-530.

Hills, G.E., Lumpkin, G.T., Singh, R.P., 1997. Opportunity recognition: Perceptions and behaviors of entrepreneurs. In P.D. Reynolds, W.D. Bygrave, W.B. Gartner, N.M. Carter, C.M. Mason, P. Davidsson, \& P.P. McDougall (Eds), Frontiers of entrepreneurship research (pp. 168-182). Wellesley, MA: Babson College Press.

Kirzner, I.M., 1973. Competition and Entrepreneurship. University of Chicago Press, Chicago, IL.

Kirzner, I.M., 1979. Perception, Opportunity and Profit. University of Chicago Press, Chicago, IL.

Lumpkin, G.T., Lichtenstein, B.B., 2005. The role of organizational learning in the opportunityrecognition process. Entrepreneurship Theory and Practice, 29, 451-472.

Miles, M. B., Huberman, A. M., 1994. Qualitative data analysis: An expanded sourcebook, $2^{\text {nd }}$ edition. Thousand Oaks, CA: Sage.

OECD, Science, technology and industry scoreboard, 2003. Retrieved from http://www.oecd.org/document/21/0,3343,fr_2649_33703_16683413_1_1_1_1,00.html.

Robson, G., Gallagher, C., Daly, M., 1993. Diversification strategy and practice in small firms. International Small Business Journal, 11(2), 37-53.

Schwartz, R., Teach, R., 1999. A model of opportunity recognition and exploitation: an empirical study of incubator firms. Presented at the 13th UIC/AMA Symposium on Marketing and Entrepreneurship Interface, Nice, June.

Schumpeter, J. A., 1934. The theory of economic development. Cambridge, MA: Harvard University Press.

Schumpeter, J.A., 1942. Capitalism, socialism and democracy. New York: Harper and Row.

Shane, S., 1999. Prior knowledge and discovery of entrepreneurial opportunities. Organization Science, 11, 448-469.

Shane, S., Venkataraman, S., 2000. The promise of entrepreneurship as a field of research, Academy of Management Review, 25, 217-226.

Sigrist, B., 1999. Entrepreneurial opportunity recognition. Paper presented at the annual UIC/AMA Symposium at the Marketing/Entrepreneurship Interface, Sofia-Antipolis, France.

Singh, R., Hills, G., Hybels, R., Lumpkin, G., 1999. Opportunity recognition through social network characteristics of entrepreneurs. In: Reynolds, P., Bygrave, W., S.Manigart, C., Mason, G., Meyer, H., Sapienza, K. (Eds.), Frontiers of Entrepreneurship Research. Babson College Press, Babson, Park, $228-241$.

Stevenson, H.H., Roberts, M.J., Grousbeck, H.I., 1985. New Business Ventures and the Entrepreneur. Irwin, Homewood, IL. 
Tether, B. S., Massini, S., 1998. Employment creation in small technological and design innovators in the U.K. during the 1980's. Small Business Economics, 11, pp 353-370.

Timmons J.A, Spinelli S., 2003. New venture creation: entrepreneurship for the $21^{\text {st }}$ Century. $6^{\text {th }}$ edition. Boston: McGraw Hill.

Venkataraman, S., 1997. The distinctive domain of entrepreneurship research: an editor's perspective. In: Katz, J., Brockhaus, R. (Eds.), Advances in Entrepreneurship, Firm Emergence, and Growth, vol. $3,119-138$.

Vesper, K., 1980. New venture strategies. New York: Prentice-Hall.

Wagner, J., 1994. The post-entry performance of new small firms in German manufacturing industries. Journal of Industrial Economics, 42(2), 141-154.

Ward, T.B., 2004. Cognition, creativity, and entrepreneurship. Journal of Business Venturing, 19(2), $173-188$.

Yin, R.K., 1994. Case study research: Design and methods (Vol. 5), Sage Publications. 